\title{
Continued Postoperative Use of Tumor Necrosis Factor- $\alpha$ Inhibitors for the Prevention of Crohn's Disease Recurrence
}

\author{
Jongwook Yu, Hye Kyung Hyun, Jihye Park, Eun Ae Kang, Soo Jung Park, Jae Jun Park, Tae II Kim, Won Ho \\ Kim, and Jae Hee Cheon \\ Department of Internal Medicine and Institute of Gastroenterology, Yonsei University College of Medicine, Seoul, Korea
}

\section{Article Info}

Received February 8, 2021

Revised June 12, 2021

Accepted June 14, 2021

Published online August 24, 2021

Corresponding Author

Jae Hee Cheon

ORCID https://orcid.org/0000-0002-2282-8904

E-mail Geniushee@yuhs.ac
Background/Aims: Many patients with Crohn's disease (CD) undergo intestinal resection during the disease course. Despite surgery, postoperative recurrence (POR) commonly occurs. Although postoperative use of tumor necrosis factor $\alpha$ (TNF- $\alpha$ ) inhibitors is known to be effective in preventing POR, few studies have evaluated the effectiveness of continuing the same TNF- $\alpha$ inhibitors postoperatively in patients who received TNF-a inhibitors before surgery.

Methods: This retrospective observational study was performed in a single tertiary medical center. We retrospectively reviewed patients who had undergone the first intestinal resection due to $C D$ and divided them into two groups: TNF- $\alpha$ inhibitor users in both the preoperative and postoperative periods, and TNF- $\alpha$ inhibitor users in only the preoperative period. We compared the clinical outcomes between these two groups.

Results: In total, 45 patients who used TNF- $\alpha$ inhibitors preoperatively were recruited. Among them, TNF- $\alpha$ inhibitors were used postoperatively in 20 patients (44.4\%). The baseline characteristics except age at diagnosis were similar in both groups. The rates of surgical and endoscopic recurrence were not different between the two groups, but the cumulative clinical recurrence rate was significantly lower in the postoperative TNF- $\alpha$ inhibitors group (log-rank $p=0.003$ ). In multivariate Cox regression analysis, postoperative TNF- $\alpha$ inhibitors use was significantly associated with a decreased risk of clinical recurrence (adjusted hazard ratio, 0.204; 95\% confidence interval, 0.060 to $0.691 ; p=0.011$ ).

Conclusions: Continuing TNF- $\alpha$ inhibitors postoperatively in patients who were receiving TNF- $\alpha$ inhibitors before surgery significantly reduced the rate of clinical recurrence. For patients with $C D$ who received TNF- $\alpha$ inhibitors preoperatively, continuing their use after surgery could be recommended. (Gut Liver 2022;16:414-422)

Key Words: Crohn disease; Postoperative recurrence; Tumor necrosis factor-alpha inhibitor

\section{INTRODUCTION}

Crohn's disease (CD) is a chronic inflammatory bowel disease with an unknown, complex pathophysiology associated with genetics, immunology, and environmental factors; there is no curative treatment for the disease. ${ }^{1}$ The incidence and prevalence of $\mathrm{CD}$ are rising globally, and the condition is associated with enormous economic and social burdens. ${ }^{2,3}$ Various types of medications, such as 5-aminosalicylic acids, immunomodulators (azathioprine, 6-mercaptopurine, and methotrexate), small molecules/ biologic agents, such as tumor necrosis factor $\alpha$ (TNF- $\alpha$ ) inhibitors, and biosimilars, have been used to improve the course of $\mathrm{CD}^{4-6}$

Despite intensive medical treatment including new classes of medications, a significant number of patients with $\mathrm{CD}$ still require intestinal resection at some point in their disease course. ${ }^{7}$ Even patients who have previously received surgery might have to undergo repeated surgeries. In clinical practice, all possible treatment options, such as immunomodulators and biologics, are undertaken to delay surgery in the clinical course of $\mathrm{CD}{ }^{4}$ 
If patients must inevitably undergo surgery, effective postoperative management is an important step to reduce postoperative recurrence (POR). POR has become one of the major issues in the management of $\mathrm{CD}$. Various factors are known to affect the POR of CD. Patient factors, such as smoking status and family history, and disease factors, such as age at disease onset, disease duration, disease extent, location, behavior, and surgery-related factors, are known to be associated with POR. ${ }^{1,7-11}$ Therefore, endeavors have been made to delay the disease course for preventing POR by early detection and management. Although the effectiveness of azathioprine has been proven for preventing POR, recent studies have reported that TNF- $\alpha$ inhibitors are superior to azathioprine in this regard. ${ }^{12-14}$ After risk assessment, postoperative prophylactic TNF- $\alpha$ inhibitors are commonly prescribed based on their proven efficacy in decreasing the rate of POR. ${ }^{15,16}$ However, most studies have focused on the preventive effects of TNF- $\alpha$ inhibitors for POR. ${ }^{17,18}$ Additionally, due to the concerns about immediate postoperative complications of TNF- $\alpha$ inhibitors, they are usually discontinued few weeks before elective surgery. ${ }^{19-23}$ After discontinuing TNF- $\alpha$ inhibitors before surgery, the decision to restart or discontinue them depend on each clinician's assessment, due to the lack of evidence. Additionally, there have been few studies about the association between preoperative use of TNF- $\alpha$ inhibitors and POR. In this study, we investigated whether the same TNF- $\alpha$ inhibitors used postoperatively are effective in preventing POR in patients with CD who used TNF- $\alpha$ inhibitors before surgery.

\section{MATERIALS AND METHODS}

\section{Study population}

This was a retrospective observational study conducted in a single tertiary medical center in Korea (Severance Hospital, Yonsei University College of Medicine, Seoul). We retrospectively investigated patients who underwent the first intestinal resection due to CD between January 2010 and August 2020. In this study, appendectomy, stricture-plastic surgery, and perianal surgeries, such as fistulectomy, were not categorized as intestinal resection surgery due to $\mathrm{CD}$.

\section{Data collection}

We retrospectively analyzed endoscopic, clinical, and surgical data of patients with $\mathrm{CD}$. Although the data were collected retrospectively from electronic medical charts and colonoscopy or radiologic reports in our hospital, all clinical variables were prospectively recorded according to patient analysis. We investigated the patients' age, age at diagnosis, sex, smoking history, family history, previous surgical history, and Montreal classification (A: age at diagnosis, L: disease location, B: disease behavior). ${ }^{11}$ We further investigated the events and dates of surgical, endoscopic, and clinical recurrences. The definitions of recurrences are described in "the definition of POR" section. We used the CD Activity Index (CDAI) to standardize patients' disease activity. ${ }^{24}$ Physicians evaluated and calculated CDAI through history, physical examination, and laboratory findings during every patient visit. We investigated each patient's medical records as well as endoscopic and surgery reports to analyze the histories of cumulative events such as additional surgery, hospitalization, disease exacerbation, and preoperative and postoperative medications for managing CD. All histories of prescribed medications, such as 5-aminosalicylic acids, immunomodulators (azathioprine, 6-mercaptopurine, methotrexate), and biologic agents were analyzed preoperatively and/or postoperatively. In this study, preoperative biologics use was defined as continuous, regular use (maintenance dose) of biologics before surgery. Continued use of biologics postoperatively was defined as starting biologics use within 3 months after surgery in consideration of the temporary perioperative discontinuation of biologic agents. ${ }^{18}$ Starting biologics after 3 months of surgery was not defined as continued use of biologics postoperatively. Concomitant immunomodulators were maintained after surgery in most patients if there were no contraindications such as leukopenia or combined infections. The data regarding this article can be shared upon request to the corresponding author.

\section{Study design}

In this study, we mainly focused on the POR (endoscopic, clinical, and surgical) according to the postoperative use of TNF- $\alpha$ inhibitors in patients with CD who were administered TNF- $\alpha$ inhibitors preoperatively. In other words, we divided patients who had undergone the first intestinal resection due to CD into two groups: TNF- $\alpha$ inhibitors users both in the preoperative and postoperative periods, and TNF- $\alpha$ inhibitors users only in preoperative period. We then compared the clinical outcomes while focusing on the endoscopic, clinical, and surgical recurrences between the two groups.

\section{Definitions}

\section{1) Endoscopic recurrence}

We analyzed the data of follow-up colonoscopies after surgery through electronic medical records and colonoscopic or radiologic reports and images. Endoscopic images were reviewed and categorized to show remission 
(Rutgeerts score of i0 or i1) or recurrence (Rutgeerts score i2 or more) according to the Rutgeerts score. ${ }^{25}$

\section{2) Clinical recurrence}

Clinical recurrence was defined as the first episode of symptomatic exacerbation of CD after surgery. In our study, a CDAI > 200 was considered to indicate clinical recurrence. ${ }^{26}$ If clinical symptoms were exacerbated by other causes, such as infectious colitis and acute gastroenteritis, the condition was not considered as the clinical recurrence of CD.

\section{3) Surgical recurrence}

Surgical recurrence was defined as a condition requiring an additional intestinal resection during follow-up that was related to $\mathrm{CD} .{ }^{26}$ Early postoperative complications, such as anastomotic leak, abscess drainage, or surgical site infections that occurred within 1 month after initial surgery were not considered as surgical recurrence. Moreover, surgeries performed for reasons other than $\mathrm{CD}$, such as malignancies in the abdominal cavity or infections, were not regarded as surgical recurrence.

\section{Statistical analysis}

We analyzed the baseline characteristics using the
Mann-Whitney U test for continuous variables and the chisquare test or the Fisher exact test for categorical variables. Non-normally distributed outcomes were presented as the median and interquartile range. The Kaplan-Meier survival analysis was used to estimate the cumulative recurrence rate in patients according to the variables. Univariable analysis was performed using the Cox proportionalhazards model to identify factors associated with increased risk of recurrences. Factors associated with recurrences with a p-value of less than 0.20 in the univariable analysis were entered in the multivariable model. Multivariable analysis was performed using the Cox regression model to control for multiple risk factors that could influence recurrence. Hazard ratios and corresponding 95\% confidence intervals were calculated. Results were considered statistically significant at $\mathrm{p}$-values $<0.05$. All statistical analyses were performed using SPSS version 20 software (IBM Corp., Armonk, NY, USA).

\section{Ethical considerations}

This study was performed in accordance with the ethical guidelines of the 1975 Declaration of Helsinki, and was approved by the Institutional Review Board of Severance Hospital, Seoul, South Korea (IRB number: 4-2020-1297). The informed consent was waived.

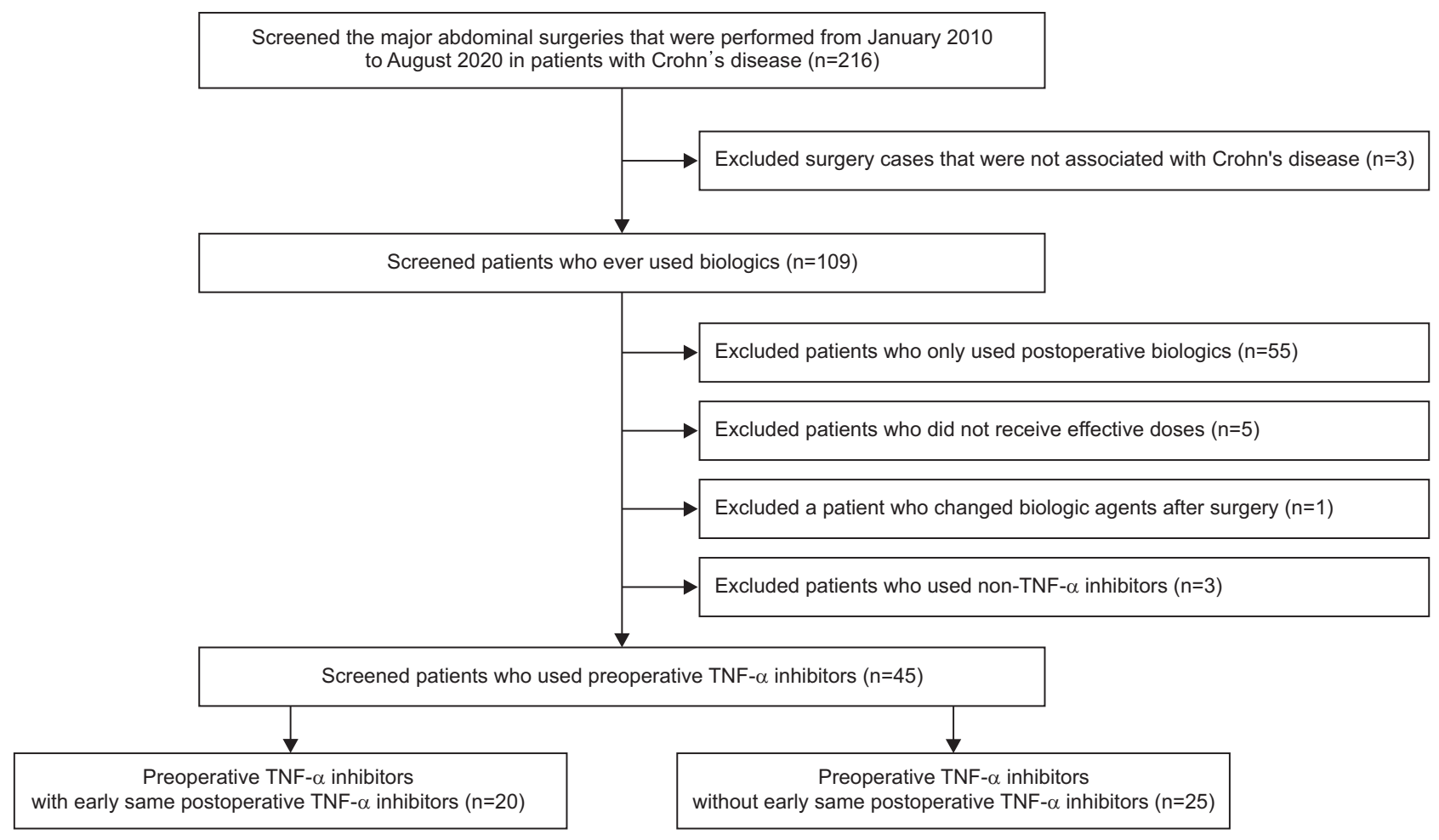

Fig. 1. Flowchart of patient inclusion.

TNF, tumor necrosis factor. 


\section{RESULTS}

\section{Baseline patient characteristics}

We recruited patients with $\mathrm{CD}$ who had undergone the first intestinal resection in their disease course between January 2010 and August 2020. A total of 216 patients were selected through medical chart review. Among them, three cases related to colorectal cancer were excluded. Among 213 patients, a total of 109 patients were exposed to biolog- ic agents. Among them, 55 patients were treated with biologic agents only postoperatively. Additionally, five patients with ineffective therapeutic dosage (in induction phase: two patients; discontinuation for long time [more than 3 months]: two patients; discontinuation due to side effects: one patient), one patient who changed biologic agents after surgery and three patients who maintained vedolizumab were excluded. We finally selected 45 patients who used preoperative TNF- $\alpha$ inhibitors with maintenance doses

Table 1. Demographics and Clinical Characteristics of the Patients

\begin{tabular}{|c|c|c|c|c|}
\hline Characteristic & $\begin{array}{l}\text { Preoperative TNF-a } \\
\text { inhibitors }(+)(n=45)\end{array}$ & $\begin{array}{l}\text { With POT } \\
\qquad(n=20)\end{array}$ & $\begin{array}{l}\text { Without POT } \\
\qquad(n=25)\end{array}$ & p-value \\
\hline Male sex & $28(62.2)$ & 14 (70.0) & $14(56.0)$ & 0.336 \\
\hline Age at diagnosis, yr & $24.0(19.0-30.0)$ & $22.0(16.3-28.0)$ & $25.0(20.5-34.0)$ & 0.053 \\
\hline Time from diagnosis to surgery, mo & $80.0(55.0-118.0)$ & $71.5(51.5-110.0)$ & $92.0(55.0-127.0)$ & 0.607 \\
\hline Time from diagnosis to the first biologics, mo & $51.0(31.0-75.0)$ & $53.5(32.8-79.0)$ & $45.0(29.5-80.0)$ & 0.508 \\
\hline Age $(A)$ & & & & 0.012 \\
\hline A1 (<16 yr) & $5(11.1)$ & $5(25.0)$ & 0 & \\
\hline A2 (17-40 yr) & 37 (82.2) & $15(75.0)$ & $22(88.0)$ & \\
\hline A3 (>40 yr) & $3(6.7)$ & 0 & $3(12.0)$ & \\
\hline Disease extent (L) & & & & 0.663 \\
\hline L1 (ileal) & $8(17.8)$ & $3(15.0)$ & $5(20.0)$ & \\
\hline L2 (colonic) & 0 & 0 & 0 & \\
\hline L3 (ileocolonic) & 37 (82.2) & $17(85.0)$ & $20(80.0)$ & \\
\hline L4 (upper) & 0 & 0 & 0 & \\
\hline Disease characteristics & & & & 0.154 \\
\hline B1 (non-stricturing, non-penetrating) & $10(22.2)$ & $6(30.0)$ & $4(16.0)$ & \\
\hline B2 (stricturing) & $12(26.7)$ & $7(35.0)$ & $5(20.0)$ & \\
\hline B3 (penetrating) & $23(51.1)$ & $7(35.0)$ & $16(64.0)$ & \\
\hline Perianal disease & $28(62.2)$ & $12(60.0)$ & $16(64.0)$ & 0.783 \\
\hline Smoking & & & & 0.657 \\
\hline Never-smoker & 37 (82.2) & 17 (85.0) & $20(80.0)$ & \\
\hline Former smoker & $7(15.6)$ & $3(15.0)$ & $4(16.0)$ & \\
\hline Current smoker & $1(2.2)$ & 0 & $1(4.0)$ & \\
\hline Smoking after surgery & 0 & 0 & 0 & NA \\
\hline Appendectomy & $5(11.1)$ & $3(15.0)$ & $2(8.0)$ & 0.458 \\
\hline Family history & $2(4.4)$ & 0 & $2(8.0)$ & 0.196 \\
\hline Height, $\mathrm{cm}$ & $168.0(163.0-172.5)$ & $167.5(161.5-169.5)$ & $170.0(164.0-173.5)$ & 0.243 \\
\hline Weight, kg & $53.0(48.0-61.0)$ & $51.0(42.0-61.8)$ & $55.0(50.0-61.0)$ & 0.262 \\
\hline Surgical recurrence & $4(8.9)$ & $1(5.0)$ & $3(12.0)$ & 0.412 \\
\hline Endoscopic recurrence & $14 / 30(46.7)$ & $4 / 13(30.8)$ & $10 / 17(58.8)$ & 0.127 \\
\hline Clinical recurrence & $22(48.9)$ & $3(15.0)$ & $19(76.0)$ & $<0.001$ \\
\hline Mortality, No. (\%) & $1(2.2)^{*}$ & 0 & $1(4.0)^{*}$ & 0.366 \\
\hline Total number of preoperative biologic agents & & & & 0.241 \\
\hline 1 & $31(68.9)$ & $16(80.0)$ & $15(60.0)$ & \\
\hline 2 & $12(26.7)$ & $4(20.0)$ & $8(32.0)$ & \\
\hline 3 & $2(4.4)$ & 0 & $2(8.0)$ & \\
\hline TNF-a inhibitors just before surgery & & & & 0.540 \\
\hline Infliximab & $27(60.0)$ & $13(65.0)$ & $14(56.0)$ & \\
\hline Adalimumab & $18(40.0)$ & $7(35.0)$ & $11(44.0)$ & \\
\hline TNF-a inhibitors just after surgery & - & & - & - \\
\hline Infliximab & & 13 (65.0) & & \\
\hline Adalimumab & & $7(35.0)$ & & \\
\hline Concomitant use of immunomodulators & 31 (68.9) & $16(80.0)$ & 15 (60.0) & 0.150 \\
\hline
\end{tabular}

Data are presented as number (\%), median (IQR), or number/number (\%).

TNF, tumor necrosis factor; POT, postoperative TNF- $\alpha$ inhibitors; IQR, interquartile range; NA, data not available for statistical analysis.

*Time from surgery to death, 13 months. 
(Fig. 1). Postoperative TNF- $\alpha$ inhibitors were used in 20 patients, but not in the other 25 patients. Among the 20 patients, infliximab was most commonly used preoperatively (infliximab, $\mathrm{n}=13,65.0 \%$; adalimumab, $\mathrm{n}=7,35.0 \%$ ). After surgery, all the patients continued using the same TNF- $\alpha$ inhibitors (Table 1).

The baseline patient characteristics were similar except for the age at diagnosis (Table 1). On evaluating the age at diagnosis according to the Montreal classification, the proportion of Al (age $<16$ years) was higher in postoperative TNF- $\alpha$ inhibitors users than in non-users $(25.0 \%$ vs $0 \%$, $\mathrm{p}=0.012$ ). The total number and characteristics of biologics used preoperatively were not significantly different between the groups $(\mathrm{p}=0.241)$ (Table 1). Concomitant use of immunomodulatory agents was not significantly different between the groups $(80.0 \%$ in postoperative TNF- $\alpha$ inhibitors users vs $60.0 \%$ in postoperative TNF- $\alpha$ inhibitors nonusers, $\mathrm{p}=0.150$ ) (Table 1 ).

\section{Postoperative recurrence}

We analyzed three classes of recurrence (endoscopic, clinical, and surgical recurrences). The rates of surgical and endoscopic recurrences were not significantly different between the two groups, but clinical recurrence was significantly lower in patients treated with postoperative biologics $(n=3[15.0 \%]$ vs $n=19$ [76.0\%], $\mathrm{p}<0.001)$ (Table 1$)$. The time from initial surgery to clinical recurrence was shorter than in surgical recurrence ( 31.5 months [range, 8.5 to 56.8 ] vs 93.0 months [range, 57.8 to 111.0 ]), although both the time from surgery to each recurrence and the time from diagnosis to each recurrence were not significantly different between groups (Table 2). The median CDAI was 289.5 (range, 245.0 to 320.0 ) at the point of clinical recurrence (Table 2). The median C-reactive protein at clinical recurrence was $10.6 \mathrm{mg} / \mathrm{L}$ (range, 4.5 to $19.0 \mathrm{mg} / \mathrm{L}$ ), which was slightly higher than normal range $(<10 \mathrm{mg} / \mathrm{L}){ }^{27}$

The Kaplan-Meier analysis revealed that the cumulative clinical recurrence rate was significantly lower in the postoperative TNF- $\alpha$ inhibitors group (log-rank $\mathrm{p}=0.003$ ) (Fig. 2 ), but cumulative surgical recurrence rate was not significantly different between groups (log-rank $\mathrm{p}=0.941)$ (Fig. 2).

In univariable and multivariable analyses with the Cox

Table 2. Characteristics Related to Recurrences

\begin{tabular}{lcccc}
\hline \multicolumn{1}{c}{ Characteristics } & Total $(\mathrm{n}=45)$ & With POT $(\mathrm{n}=20)$ & Without POT $(\mathrm{n}=25)$ & $\mathrm{p}$-value \\
\hline Clinical recurrence & $22(48.9)$ & $3(15.0)$ & $19(76.0)$ & $<0.001$ \\
$\quad$ Time from surgery to CR, mo & $31.5(8.5-56.8)$ & $60.0(9.0-87.0)$ & $31.0(7.0-54.0)$ & 0.315 \\
Time from diagnosis to CR, mo & $139.0(81.5-176.3)$ & $173.0(158.0-259.0)$ & $124.0(62.0-172.0)$ & 0.077 \\
CDAl at CR & $289.5(245.0-320.0)$ & $354.0(234.0-391.0)$ & $286.0(246.0-313.0)$ & 0.363 \\
CRP at CR, mg/L & $10.6(4.5-19.0)$ & $9.4(6.8-26.9)$ & $11.7(2.8-17.5)$ & 0.811 \\
Surgical recurrence & $4(8.9)$ & $1(5.0)$ & $3(12.0)$ & 0.412 \\
Time from surgery to SR, mo & $93.0(57.8-111.0)$ & 102.0 & $84.0(49.0-114.0)$ & 0.655 \\
Time from diagnosis to SR, mo & $180.5(153.3-204.8)$ & 172.0 & $189.0(147.0-210.0)$ & 0.655 \\
\hline
\end{tabular}

Data are presented as number (\%) or median (IQR).

TNF, tumor necrosis factor; POT, postoperative TNF-a inhibitors; CR, clinical recurrence; CDAl, Crohn's Disease Activity Index; CRP, C-reactive protein; SR, surgical recurrence; IQR, interquartile range.
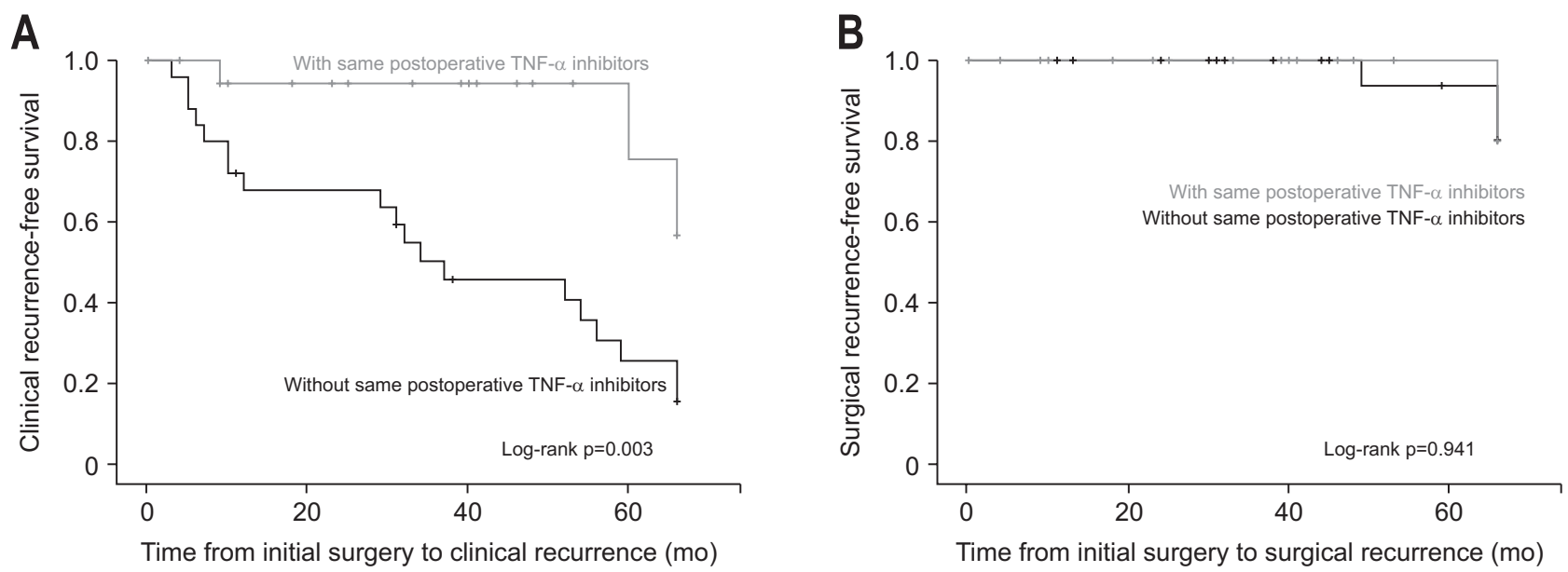

Fig. 2. Kaplan-Meier curves. (A) Cumulative clinical recurrence-free survival. (B) Cumulative surgical recurrence-free survival.

TNF, tumor necrosis factor. 
Table 3. Univariable and Multivariable Cox Regression Analyses for Recurrences

\begin{tabular}{|c|c|c|c|c|}
\hline \multirow{2}{*}{ Variable } & \multicolumn{2}{|c|}{ Univariable analysis } & \multicolumn{2}{|c|}{ Multivariable analysis } \\
\hline & $\mathrm{HR}(95 \% \mathrm{Cl})$ & $\mathrm{p}$-value & Adjusted HR (95\% CI) & p-value \\
\hline \multicolumn{5}{|l|}{ Surgical recurrence } \\
\hline Early postop TNF-a inhibitors & $0.922(0.096-8.864)$ & 0.944 & & \\
\hline Concomitant azathioprine & $0.382(0.054-2.719)$ & 0.336 & & \\
\hline Time from diagnosis to initial surgery & 1.002 (0.979-1.027) & 0.849 & & \\
\hline Time from diagnosis to the first TNF-a inhibitors & $1.021(0.991-1.051)$ & 0.169 & $1.021(0.991-1.051)$ & 0.169 \\
\hline Smoking history & $N A^{*}$ & & & \\
\hline Family history & $N A^{*}$ & & & \\
\hline Perianal disease & $1.388(0.144-13.348)$ & 0.776 & & \\
\hline B3 (penetrating) & $0.883(0.124-6.269)$ & 0.901 & & \\
\hline $\mathrm{A} 1(<16 \mathrm{yr})$ & $N A^{*}$ & & & \\
\hline \multicolumn{5}{|l|}{ Clinical recurrence } \\
\hline Early postop TNF-a inhibitors & $0.194(0.057-0.656)$ & 0.008 & $0.204(0.060-0.691)$ & 0.011 \\
\hline Concomitant azathioprine & $0.436(0.186-1.023)$ & 0.056 & $0.564(0.228-1.393)$ & 0.214 \\
\hline Time from diagnosis to initial surgery & $1.006(0.997-1.015)$ & 0.177 & $1.003(0.994-1.013)$ & 0.501 \\
\hline Time from diagnosis to the first TNF-a inhibitors & $1.004(0.992-1.015)$ & 0.544 & & \\
\hline Smoking history & $1.425(0.478-4.252)$ & 0.526 & & \\
\hline Family history & $1.300(0.170-9.968)$ & 0.801 & & \\
\hline Perianal disease & $2.047(0.753-5.562)$ & 0.160 & $1.626(0.562-4.708)$ & 0.370 \\
\hline B3 (penetrating) & $1.235(0.527-2.890)$ & 0.627 & & \\
\hline$A 1(<16 y r)$ & $0.370(0.050-2.751)$ & 0.331 & & \\
\hline
\end{tabular}

$\mathrm{HR}$, hazard ratio; $\mathrm{Cl}$, confidence interval; TNF, tumor necrosis factor.

*NA: data not available for statistical analysis due to the small number of surgical recurrences.

regression model, none of the factors were significantly related to surgical recurrence. For clinical recurrence, postoperative TNF- $\alpha$ inhibitors use was significantly associated with a decreased risk of clinical recurrence (adjusted hazard ratio, 0.204 ; $95 \%$ confidence interval, 0.060 to 0.691 ; $\mathrm{p}=0.011$ ) (Table 3).

\section{DISCUSSION}

$\mathrm{CD}$ requires long-term medical and even surgical management due to its chronic relapsing-remitting disease course. Considering its long-term course, the most efficient methods to maintain disease remission and control disease exacerbation should be instituted. Inflammatory bowel disease specialists have considered surgery as an indispensable treatment option in managing $\mathrm{CD}$, although intensive medical treatment should be administered before surgery to delay surgery to the maximum extent. However, if surgery is required due to symptom aggravation or loss of response to medical treatment, it is mandatory to set the right time for elective surgery through discussion with a surgical team.

For patients with $\mathrm{CD}$, if surgery is inevitably performed, the first surgery might be a significant turning point to adjust treatment strategies. Even if surgery is successfully performed, it is well known that a substantial number of patients still need repeated surgeries during the course of the disease. Therefore, various methods and strategies to prevent POR based on risk models have been investigated. After assessing postoperative risk, step-up treatment is recommended according to ileo-colonoscopic findings. Especially for high-risk patients (smokers or those with perforating disease features or history of previous intestinal resection), earlier use of immunomodulators and biologic agents should be considered. ${ }^{7,828-30}$

There are a few important issues regarding POR in $\mathrm{CD}$. One of the most interesting treatment strategies for patients with $\mathrm{CD}$ who have undergone surgery is the use of prophylactic biologic agents postoperatively to prevent POR. ${ }^{10,31-33}$ Although most studies proved that this strategy is effective in preventing recurrence in postoperative patients with $\mathrm{CD}$, long-term investigation is necessary, especially in terms of side effects and costs. ${ }^{15}$ Another important issue is the perioperative use of biologic agents for POR. It is important that before elective surgery, biologics are stopped for some time due to concerns about postoperative complications such as delayed wound healing. ${ }^{19-21,34}$ There have been few studies about restarting or stopping TNF- $\alpha$ inhibitors after surgery in patients who were on preoperative TNF- $\alpha$ inhibitors in maintenance dose.

In our study, considering real-world practice, we retrospectively categorized patients who underwent their first intestinal resection and used TNF- $\alpha$ inhibitors preopera- 
tively into two groups (postoperative use of TNF- $\alpha$ inhibitors vs no postoperative use of TNF- $\alpha$ inhibitors), and followed their disease courses while focusing on clinical endpoints (endoscopic, clinical, and surgical recurrences). To focus more on the long-term outcomes influenced by medical (TNF- $\alpha$ inhibitors) factors, we did not include the cases of early PORs by surgical factors. In this study, only four patients (8.9\%) experienced surgical recurrence during the follow-up period. Although patients who continued using TNF- $\alpha$ inhibitors after surgery had a lower rate of surgical recurrence, the difference was not statistically significant, probably due to the small number of cases of surgical recurrence $(1 / 20,5.0 \%$ for postoperative TNF- $\alpha$ inhibitors users vs $3 / 25,12.0 \%$ postoperative TNF- $\alpha$ inhibitors non-users; $\mathrm{p}=0.412$ ). Additionally, this finding may be explained by the relatively short duration of follow-up (median duration of follow-up after the initial surgery was 48.0 months; interquartile range, 27.5 to 84.5 months).

For endoscopic recurrences, patients who maintained TNF- $\alpha$ inhibitors after surgery had a numerically lower rate of endoscopic recurrence, although this was not statistically significant $(3 / 14,30.8 \%$ with TNF- $\alpha$ inhibitors vs $10 / 17,58.8 \%$ without TNF- $\alpha$ inhibitors; $\mathrm{p}=0.127$ ).

In our study, more than $60 \%$ of patients were concomitantly treated with azathioprine. Immunomodulators, such as azathioprine, have been known to be effective in preventing POR, although the study results are conflicting. ${ }^{35,36}$ According to recent studies, azathioprine use after the detection of endoscopic recurrence was not inferior to immediate azathioprine use after surgery in terms of clinical outcomes. ${ }^{37,38}$ Besides biologic agents, further studies are needed to determine the role of immunomodulators in POR.

On the Kaplan-Meier analysis, clinical recurrencefree survival was significantly superior in those who used TNF- $\alpha$ inhibitors preoperatively and postoperatively compared to those without TNF- $\alpha$ inhibitors use after surgery (log-rank $\mathrm{p}=0.003)$. Moreover, continuing the use of TNF- $\alpha$ inhibitors postoperatively significantly reduced the risk of clinical recurrence on the multivariable Cox regression analysis (adjusted hazard ratio, 0.204; 95\% confidence interval, 0.060 to $0.691 ; \mathrm{p}=0.011$ ).

Few studies have reported that postoperative use of TNF- $\alpha$ inhibitors reduced the occurrence of POR by aiding mucosal healing. ${ }^{39,40}$ Similarly, preoperative TNF- $\alpha$ inhibitors might improve clinical outcomes by aiding mucosal healing before surgery. In clinical practice, optimal medical treatments must be preceded to avoid surgery. However, there is a concern that the same TNF- $\alpha$ inhibitors might not be effective, especially if preoperative TNF- $\alpha$ inhibitors did not prevent surgery. In the state of maximal disease burden, no medical treatment would be effective; but if the disease burden is decreased by surgery, same TNF- $\alpha$ inhibitors might control remnant disease. Further studies are needed to prove the pathophysiology of the effects of preoperative and postoperative TNF- $\alpha$ inhibitors use in terms of preventing POR. Regueiro et al. ${ }^{41}$ reported that infliximab reduced endoscopic recurrence, although it did not reduce clinical recurrence at 76 and 104 weeks. The median time from initial surgery to clinical recurrences in our study was 31.5 months (interquartile range, 8.5 to 56.8 months), which was longer than that of the previous study (76 weeks). There is a possibility that infliximab might significantly reduce clinical recurrence if long-term follow-up was attained. In our study, the best clinical outcomes were shown in patients with both preoperative and postoperative TNF- $\alpha$ inhibitors use, suggesting that maintaining the same TNF- $\alpha$ inhibitors after surgery might be beneficial. Based on our study results, we suggest maintaining the same TNF- $\alpha$ inhibitors if TNF- $\alpha$ inhibitors were used preoperatively, and then performing early screening to evaluate and adjust medications. Furthermore, it might spare further possible treatment (biologics) options in the future. Long-term follow-up in prospective studies with a large cohort are required to prove our findings.

Our study had several limitations. First, this was a retrospective, single-center study, and variations in treatment strategies were quite small. In other words, there has been no consensus about continuing preoperatively used TNF- $\alpha$ inhibitors after surgery, and the decision was made based on each clinician's perspective and expertise. A singlecenter design could be an advantage in terms of less variance in treatment strategies. Second, a small number of patients were enrolled, and the follow-up period was relatively short. This could explain the small number of surgical recurrences in our study. Third, inflammatory markers such as fecal calprotectin, C-reactive protein, erythrocyte sedimentation rate were not examined while analyzing recurrence. If biochemical markers could be combined with other parameters, it would be helpful to screen POR in the early stage. Fourth, in this retrospective study, we did not include the specific findings about endoscopic recurrence not to draw false results due to bias because not all the patients received postoperative colonoscopy exams at a specified time after surgery.

In conclusion, continuation of preoperatively administered TNF- $\alpha$ inhibitors significantly reduced the rate of clinical recurrence of $\mathrm{CD}$ after surgery. For patients with CD who were receiving TNF- $\alpha$ inhibitors before surgery, continuing rather than stopping TNF- $\alpha$ inhibitors after surgery could be recommended. 


\section{CONFLICTS OF INTEREST}

S.J.P. and J.H.C. are editorial board members of the journal but were not involved in the peer reviewer selection, evaluation, or decision process of this article. No other potential conflicts of interest relevant to this article were reported.

\section{AUTHOR CONTRIBUTIONS}

Conceptualization: J.Y., J.H.C. Data collection and analysis: J.Y., H.K.H., J.P., E.A.K., S.J.P., J.J.P., T.I.K., W.H.K., J.H.C. Statistical analysis: J.Y., J.H.C. Writing - original draft: J.Y., J.H.C. Writing - review \& editing: J.Y., H.K.H., J.P., E.A.K., S.J.P., J.J.P., T.I.K., W.H.K., J.H.C. Approval of final manuscript: all authors.

\section{ORCID}

Jongwook Yu https://orcid.org/0000-0001-7489-2222 Hye Kyung Hyun https://orcid.org/0000-0002-6195-425X Jihye Park https://orcid.org/0000-0002-5836-8735 Eun Ae Kang Soo Jung Park Jae Jun Park Tae Il Kim Won Ho Kim Jae Hee Cheon https://orcid.org/0000-0003-0220-937X https://orcid.org/0000-0003-0699-6809 https://orcid.org/0000-0001-9974-1658 https://orcid.org/0000-0003-4807-890X https://orcid.org/0000-0002-5682-9972 https://orcid.org/0000-0002-2282-8904

\section{REFERENCES}

1. Park SH, Park JC, Lukas M, Kolar M, Loftus EV. Biosimilars: concept, current status, and future perspectives in inflammatory bowel diseases. Intest Res 2020;18:34-44.

2. Baumgart DC, Sandborn WJ. Crohn's disease. Lancet 2012;380:1590-1605.

3. Barrett JC, Hansoul S, Nicolae DL, et al. Genome-wide association defines more than 30 distinct susceptibility loci for Crohn's disease. Nat Genet 2008;40:955-962.

4. Colombel JF, Sandborn WJ, Rutgeerts P, et al. Adalimumab for maintenance of clinical response and remission in patients with Crohn's disease: the CHARM trial. Gastroenterology 2007;132:52-65.

5. Fraser AG, Orchard TR, Jewell DP. The efficacy of azathioprine for the treatment of inflammatory bowel disease: a 30 year review. Gut 2002;50:485-489.

6. Mizoguchi E, Low D, Ezaki Y, Okada T. Recent updates on the basic mechanisms and pathogenesis of inflammatory bowel diseases in experimental animal models. Intest Res 2020;18:151-167.

7. De Cruz P, Kamm MA, Prideaux L, Allen PB, Desmond PV. Postoperative recurrent luminal Crohn's disease: a systematic review. Inflamm Bowel Dis 2012;18:758-777.

8. Nos P, Domenech E. Postoperative Crohn's disease recurrence: a practical approach. World J Gastroenterol 2008; 14:5540-5548.

9. Kim SB, Cheon JH, Park JJ, et al. Risk factors for postoperative recurrence in Korean patients with Crohn's disease. Gut Liver 2020;14:331-337.

10. Michetti P. Postsurgical prophylaxis in Crohn's disease: which patients, which agents? Dig Dis 2015;33 Suppl 1:78-81.

11. Satsangi J, Silverberg MS, Vermeire S, Colombel JF. The Montreal classification of inflammatory bowel disease: controversies, consensus, and implications. Gut 2006;55:749753.

12. D'Haens GR, Vermeire S, Van Assche G, et al. Therapy of metronidazole with azathioprine to prevent postoperative recurrence of Crohn's disease: a controlled randomized trial. Gastroenterology 2008;135:1123-1129.

13. Peyrin-Biroulet L, Deltenre P, Ardizzone S, et al. Azathioprine and 6-mercaptopurine for the prevention of postoperative recurrence in Crohn's disease: a meta-analysis. Am J Gastroenterol 2009;104:2089-2096.

14. Domènech E, Mañosa M, Bernal I, et al. Impact of azathioprine on the prevention of postoperative Crohn's disease recurrence: results of a prospective, observational, long-term follow-up study. Inflamm Bowel Dis 2008;14:508-513.

15. Savarino E, Bodini G, Dulbecco P, et al. Adalimumab is more effective than azathioprine and mesalamine at preventing postoperative recurrence of Crohn's disease: a randomized controlled trial. Am J Gastroenterol 2013;108:1731-1742.

16. Armuzzi A, Felice C, Papa A, et al. Prevention of postoperative recurrence with azathioprine or infliximab in patients with Crohn's disease: an open-label pilot study. J Crohns Colitis 2013;7:e623-e629.

17. Regueiro M, Schraut W, Baidoo L, et al. Infliximab prevents Crohn's disease recurrence after ileal resection. Gastroenterology 2009;136:441-450.

18. Cañete F, Mañosa M, Casanova MJ, et al. Adalimumab or infliximab for the prevention of early postoperative recurrence of Crohn disease: results from the ENEIDA Registry. Inflamm Bowel Dis 2019;25:1862-1870.

19. Narula N, Charleton D, Marshall JK. Meta-analysis: perioperative anti-TNFa treatment and post-operative complications in patients with inflammatory bowel disease. Aliment Pharmacol Ther 2013;37:1057-1064.

20. El-Hussuna A, Theede K, Olaison G. Increased risk of postoperative complications in patients with Crohn's disease treated with anti-tumour necrosis factor a agents: a system- 
atic review. Dan Med J 2014;61:A4975.

21. Hansen TM, Targownik LE, Karimuddin A, Leung Y. Management of biological therapy before elective inflammatory bowel disease surgeries. Inflamm Bowel Dis 2019;25:16131620.

22. Kulaylat AN, Kulaylat AS, Schaefer EW, et al. The impact of preoperative anti-TNFa therapy on postoperative outcomes following ileocolectomy in Crohn's disease. J Gastrointest Surg 2021;25:467-474.

23. Billioud V, Ford AC, Tedesco ED, Colombel JF, Roblin X, Peyrin-Biroulet L. Preoperative use of anti-TNF therapy and postoperative complications in inflammatory bowel diseases: a meta-analysis. J Crohns Colitis 2013;7:853-867.

24. Best WR, Becktel JM, Singleton JW, Kern F Jr. Development of a Crohn's disease activity index. National Cooperative Crohn's Disease Study. Gastroenterology 1976;70:439-444.

25. Buisson A, Chevaux JB, Allen PB, Bommelaer G, PeyrinBiroulet L. Review article: the natural history of postoperative Crohn's disease recurrence. Aliment Pharmacol Ther 2012;35:625-633.

26. Regueiro M, Kip KE, Schraut W, et al. Crohn's disease activity index does not correlate with endoscopic recurrence one year after ileocolonic resection. Inflamm Bowel Dis 2011;17:118-126.

27. Henriksen M, Jahnsen J, Lygren I, et al. C-reactive protein: a predictive factor and marker of inflammation in inflammatory bowel disease. Results from a prospective populationbased study. Gut 2008;57:1518-1523.

28. De Cruz P, Kamm MA, Hamilton AL, et al. Crohn's disease management after intestinal resection: a randomised trial. Lancet 2015;385:1406-1417.

29. Yoo JH, Holubar S, Rieder F. Fibrostenotic strictures in Crohn's disease. Intest Res 2020;18:379-401.

30. Watanabe K. Clinical management for small bowel of Crohn's disease in the treat-to-target era: now is the time to optimize treatment based on the dominant lesion. Intest Res 2020;18:347-354.

31. De Cruz P, Kamm MA, Hamilton AL, et al. Efficacy of thiopurines and adalimumab in preventing Crohn's disease recurrence in high-risk patients: a POCER study analysis. Aliment Pharmacol Ther 2015;42:867-879.
32. Sorrentino D, Marino M, Dassopoulos T, Zarifi D, Del Bianco T. Low dose infliximab for prevention of postoperative recurrence of Crohn's disease: long term follow-up and impact of infliximab trough levels and antibodies to infliximab. PLoS One 2015;10:e0144900.

33. Kotze PG, Yamamoto T, Danese S, et al. Direct retrospective comparison of adalimumab and infliximab in preventing early postoperative endoscopic recurrence after ileocaecal resection for crohn's disease: results from the MULTIPER database. J Crohns Colitis 2015;9:541-547.

34. Kopylov U, Ben-Horin S, Zmora O, Eliakim R, Katz LH. Anti-tumor necrosis factor and postoperative complications in Crohn's disease: systematic review and meta-analysis. Inflamm Bowel Dis 2012;18:2404-2413.

35. Jones GR, Kennedy NA, Lees CW, Arnott ID, Satsangi J. Systematic review: the use of thiopurines or anti-TNF in post-operative Crohn's disease maintenance. Progress and prospects. Aliment Pharmacol Ther 2014;39:1253-1265.

36. Doherty GA, Miksad RA, Cheifetz AS, Moss AC. Comparative cost-effectiveness of strategies to prevent postoperative clinical recurrence of Crohn's disease. Inflamm Bowel Dis 2012;18:1608-1616.

37. Guo Z, Cai X, Liu R, et al. Immediate prophylactic vs endoscopic or symptomatic-driven azathioprine treatment to prevent surgical recurrence after intestinal resection for Crohn's disease. Colorectal Dis 2018;20:O267-O276.

38. Ferrante M, Papamichael K, Duricova D, et al. Systematic versus endoscopy-driven treatment with azathioprine to prevent postoperative ileal Crohn's disease recurrence. J Crohns Colitis 2015;9:617-624.

39. López-Sanromán A, Vera-Mendoza I, Domènech E, et al. Adalimumab vs azathioprine in the prevention of postoperative Crohn's disease recurrence: a GETECCU randomised trial. J Crohns Colitis 2017;11:1293-1301.

40. Allocca M, Landi R, Bonovas S, et al. Effectiveness of mesalazine, thiopurines and tumour necrosis factor antagonists in preventing post-operative Crohn's disease recurrence in a real-life setting. Digestion 2017;96:166-172.

41. Regueiro M, Feagan BG, Zou B, et al. Infliximab reduces endoscopic, but not clinical, recurrence of Crohn's disease after ileocolonic resection. Gastroenterology 2016;150:1568-1578. 